Note

\title{
Mutation analysis of the SDHB and SDHD genes in pheochromocytomas and paragangliomas: identification of a novel nonsense mutation (Q168X) in the SDHB gene
}

\author{
Yohmi Oishi ${ }^{1)}$, So Nagai ${ }^{2)}$, Miyuki Yoshida ${ }^{3)}$, Shin-ichi Fujisawa ${ }^{3)}$, Ataru Sazawa ${ }^{4)}$, Nobuo Shinohara ${ }^{4)}$, \\ Katsuya Nonomura ${ }^{4)}$, Kazuhiko Matsuno ${ }^{1), 3)}$ and Chikara Shimizu ${ }^{3)}$ \\ ${ }^{1)}$ Department of Health Sciences, Hokkaido University School of Medicine, Sapporo 060-0812, Japan \\ ${ }^{2)}$ Department of Medicine II, Hokkaido University Hospital, Sapporo 060-8648, Japan \\ ${ }^{3)}$ Division of Laboratory and Transfusion Medicine, Hokkaido University Hospital, Sapporo 060-8648, Japan \\ ${ }^{4)}$ Department of Urology, Hokkaido University Hospital, Sapporo 060-8648, Japan
}

\begin{abstract}
Pheochromocytoma (PCC) and paraganglioma (PGL) are tumors of the autonomic nervous system. The former is a tumor that occurs in only adrenal glands, and the latter can be found in the head and neck or in the thorax and abdomen. In PCC and PGL, genetic mutations account for approximately $30 \%$ of functional (secrete catecholamines) and nonfunctional cases. In addition to RET, VHL and $N F-1$, genes encoding succinate dehydrogenase complex subunit B (SDHB), subunit C (SDHC), and subunit D (SDHD) are recognized as susceptibility genes for PCC and PGL. Recently, PCC and PGL caused by genetic mutations of $S D H B, S D H C$ and $S D H D$ were established as hereditary pheochromocytoma paraganglioma syndrome (HPPS). Approximately $15 \%$ of all PCCs and PGLs are recognized as HPPS. Among these three susceptibility genes, SDHB and SDHD are known to be strongly related to HPPS. The aim of this study was to analyze SDHB and SDHD mutations in PCC and PGL patients. Among 18 patients, we identified a novel heterozygous nonsense mutation at codon 168 resulting in a CAG (glutamine) to TAG (stop) substitution (Q168X) in the SDHB gene in a patient diagnosed with solitary sporadic PGL. A number of studies have reported that SDHB mutation-associated disease demonstrates a higher rate of malignancy. However, all seven patients diagnosed with malignancy in this study did not have genetic mutation of $S D H B$ and only one patient with no malignant sign had genetic mutation of SDHB. Further accumulation of cases is necessary to confirm the association between $S D H B$ mutation and malignant potential.
\end{abstract}

Key words : Mutation analysis, SDH, Pheochromocytoma, Paraganglioma

PHEOCHROMOCYTOMA (PCC) and paraganglioma (PGL) are tumors of the autonomic nervous system and PCC is derived from chromaffin cells. In some cases, PCCs and PGLs can be associated with other endocrine tumors or nervous system diseases. Most of these tumors are benign and secrete catecholamines. Some tumors recur with metastasis within a few years after surgery and, therefore, long-term medical follow-up is needed in all cases.

Hereditary syndromes associated with PCCs are multiple endocrine neoplasia (MEN) type 2, von Hippel-Lindau disease (VHL) and neurofibromatosis

Received Jan. 21, 2010; Accepted May 11, 2010 as K10E-023 Released online in J-STAGE as advance publication May 25, 2010

Correspondence to: Chikara Shimizu, M.D., Ph.D., Division of Laboratory and Transfusion Medicine, Hokkaido University Hospital, North-14, West-5, Kita-ku, Sapporo 060-8648, Japan. E-mail: shimizch@med.hokudai.ac.jp
(NF) type 1, which are caused by genetic mutations of RET, VHL and NF-1, respectively. In 2000 and 2001, three genes, $S D H B, S D H C$, and $S D H D$, encoding subunits of the succinate dehydrogenase enzyme, a part of the mitochondrial respiratory chain, were identified as susceptibility genes for PCC and PGL [1-3]. Both SDHB $(35.4 \mathrm{~kb}, 8$ exons) and SDHC $(50.3 \mathrm{~kb}$, 6 exons) are located on chromosome 1 at $1 \mathrm{p} 35$ and 1q23, respectively. SDHD (8.9kb 4 exons) is located on 11q23. PCC and PGL caused by genetic mutation of one of these three genes are named as hereditary pheochromocytoma paraganglioma syndrome (HPPS). Among these, mutations of $S D H B$ and $S D H D$ play pivotal pathogenic roles in HPPS compared with those of $S D H C[4,6,9]$. An Italian study showed that genetic mutations account for approximately $30 \%$ of functional and non-functional cases of PCC and PGL, of which approximately $15 \%$ were recognized as 
Table 1 Characteristics of the patients.

\begin{tabular}{|c|c|c|c|c|c|}
\hline No. & $\begin{array}{c}\text { Sex, age at } \\
\text { diagnosis (yr) }\end{array}$ & $\begin{array}{c}\text { Primary tumor } \\
\text { location, size }(\mathrm{cm})\end{array}$ & Metastatic location & $\begin{array}{l}\text { Family history } \\
\text { of PCC/PGL }\end{array}$ & Additional diagnosis \\
\hline 1 & $\mathrm{~F}, 61$ & Adrenal, 8.0 & Negative & Negative & \\
\hline 2 & $\mathrm{~F}, 54$ & Adrenal, 6.0 & Negative & Positive & \\
\hline 3 & F, 58 & Adrenal, 6.5 & Liver, Lung & Negative & \\
\hline 4 & $\mathrm{~F}, 67$ & Adrenal, 3.0 & Negative & Negative & \\
\hline 5 & M, 50 & Bilateral adrenal, ND & $\begin{array}{c}\text { Bone } \\
\text { Lymph node }\end{array}$ & Positive & $\begin{array}{l}\text { VHL disease*, Islet cell tumor } \\
\text { Cerebellar tumor, Aortic dissection }\end{array}$ \\
\hline 6 & $\mathrm{~F}, 75$ & Adrenal, 10.0 & Lung & Negative & Ovarian tumor \\
\hline 7 & M, 58 & Adrenal, 2.8 & Negative & Negative & Cephalic lipoma \\
\hline 8 & M, 36 & Abdominal, 6.5 & Negative & Negative & \\
\hline 9 & M, 57 & Adrenal, 6.0 & $\begin{array}{c}\text { Lung } \\
\text { Lymph node }\end{array}$ & Negative & $\begin{array}{l}\text { Cardiac infarction, Diabetes } \\
\text { Cerebral hemorrhage }\end{array}$ \\
\hline 10 & M, 55 & Adrenal, 6.0 & Negative & Negative & Cardiac infarction, Diabetes \\
\hline 11 & $\mathrm{~F}, 65$ & Adrenal, ND & Liver, Lymph node & Negative & \\
\hline 12 & M, 19 & Adrenal, 5.4 & Negative & Negative & Fundus hemorrhage, Cardiac arrest \\
\hline 13 & F, 68 & Abdominal, 1.0 & Lymph node & Negative & Cerebral hemorrhage \\
\hline 14 & M, 24 & Abdominal, 2.2 & Negative & Positive & VHL disease* \\
\hline 15 & M, 30 & Abdominal, ND & $\begin{array}{l}\text { Bone, Liver, } \\
\text { Lymph node }\end{array}$ & Positive & Diabetes \\
\hline 16 & M, 73 & Adrenal, 4.0 & Negative & Negative & Diabetes \\
\hline 17 & M, 78 & Bilateral adrenal, 2.3 & Negative & Negative & \\
\hline 18 & F, 17 & Adrenal, 5.4 & Negative & Negative & \\
\hline
\end{tabular}

ND, not determined; M, male; F, female, *No.5 is the father of No.14.

HPPS [4]. SDHA, encoding another subunit of the succinate dehydrogenase enzyme, lies on $5 \mathrm{p} 15$ and is composed of 15 exons spread over a genomic region of $38.4 \mathrm{~kb}$. Genetic mutation of SDHA causes Leigh syndrome, a subacute necrotizing encephalomyelopathy during infancy.

$S D H$ mutations are widely distributed along the gene with no hot spots. To date, several studies in Western countries [4-9] have revealed associations between mutated genes (genotype) and clinical characteristics (phenotype) of patients. Patients with mutation of $S D H B$ show a high prevalence of abdominal PGL with malignant potential as the initial tumor. In contrast, those with SDHD mutation show multiple benign PGL lesions on the head and neck as the main tumor. However, there is no evidence as to whether these associations hold among Japanese cases. Since there are few reports on $S D H$ mutations in HPPS in Asian countries [10,11], we analyzed SDHB and SDHD mutations in 18 Japanese patients diagnosed with PCC and/or PGL.

\section{Patients and Methods}

This study included 18 Japanese patients with PCC and/or PGL who were surgically treated at Hokkaido University Hospital during 2001-2009. We obtained written informed consent from all patients according to the medical ethics committee of Hokkaido University for the use of human materials for scientific purpose. Patients who presented with a head and neck or thoracic PGL were not included in this study. Four of the 18 patients had a family history of PCC or PGL, and two of them were parent and child suffered from VHL. Clinical and pathological characteristics of the 18 patients are shown in Table 1.

We performed genetic sequencing of the 8 exons of $S D H B$ and 4 exons of SDHD using tumor specimens. Genomic DNA was isolated by using the DNeasy Blood \& Tissue Kit (QIAGEN, Tokyo, Japan). Each exon of the SDHB and SDHD genes was amplified using AmpliTaq Gold 360 Master Mix (Applied Biosystems, Foster City, CA, USA) according to the manufacturer's instruction. Briefly, PCR amplifications were performed in $20 \mu \mathrm{L}$ reactions and the conditions were as follows: initial denaturation at $95{ }^{\circ} \mathrm{C}$ for $9 \mathrm{~min}$, then 35 cycles of denaturation at $95{ }^{\circ} \mathrm{C}$ for 15 sec, annealing at $51^{\circ} \mathrm{C}$ for $30 \mathrm{sec}$, and extension at 72 ${ }^{\circ} \mathrm{C}$ for $30 \mathrm{sec}$, and a final extension at $72{ }^{\circ} \mathrm{C}$ for $7 \mathrm{~min}$. The nucleotide sequences of the primers used are list- 
Table 2 List of primers in PCR.

\begin{tabular}{|c|c|c|c|}
\hline \multicolumn{2}{|c|}{ Gene } & \multirow{2}{*}{$\begin{array}{l}\text { Forward primer sequence }\left(5^{\prime}-3^{\prime}\right) \\
\text { CCCTTTCTGAGAAGGTCACG }\end{array}$} & \multirow{2}{*}{$\begin{array}{l}\text { Reverse primer sequence }\left(5^{\prime}-3^{\prime}\right) \\
\text { AGGCAGTCTCTGTGGCTTTC }\end{array}$} \\
\hline \multirow{8}{*}{$S D H B$} & exon 1 & & \\
\hline & exon 2 & TTTTTCCTTTTTGTGAACTTT & AAGCATGTCCCTAAATCAAA \\
\hline & exon 3 & GAACTTTACATAAATACCACTGGA & CTATCAGCTTTGGCCAGC \\
\hline & exon 4 & ATGGGTGAGGTGTGTTAATG & TGCAAATAAAAACAAAACCA \\
\hline & exon 5 & TGATGATGGAATCTGATCCT & CAGATTGAAACAATAAATAGGGA \\
\hline & exon 6 & ССТСТСТТТТСТССССАТАС & CAGCAATCTATTGTCCTCTTG \\
\hline & exon 7 & AGCTAATCATCCCTGGTTTT & TTGTGAGCACATGCTACTTC \\
\hline & exon 8 & GTGGGTTTTCCCTTTCAGTT & CGGCAAGTAAAGGAACAGGT \\
\hline \multirow{4}{*}{$S D H D$} & exon 1 & ATTGTCGCCTAAGTGGTTCC & AGGCTACGCTAAGCACCTCA \\
\hline & exon 2 & CAGTCCTGTTAAAGG & AGGTAAAGATGGCTAGAGCC \\
\hline & exon 3 & GGGTTACTGTGTGGCATATG & CAGCAAACAAACTGAGCAGA \\
\hline & exon 4 & GGGCAGCCAAGTTATCTGTA & CAGAGGCAAAGAGGCATACA \\
\hline
\end{tabular}

ed in Table $2[1,12]$. Then, the PCR product was purified with QIA quick PCR Purification Kit (QIAGEN), and direct sequence analysis was performed with a Big Dye Terminator sequencing kit version 1.1 (Applied Biosystems), using the same primers on both strand. After direct sequence analysis, we determined the genetic mutation by sequencing of PCR products subcloned into pGEM ${ }^{\circledR}-\mathrm{T}$ Easy Vector (Promega, Madison, WI, USA).

\section{Results and Discussion}

We sequenced the SDHB and SDHD genes in 18 Japanese patients with PCC and/or PGL. A novel heterozygous nonsense mutation of $\mathrm{CAG}>\mathrm{TAG}$ (Q168X) in the SDHB gene resulting in a glutamineto-stop substitution was identified (Fig. 1) in one patient (No.8). Further, the single nucleotide polymorphism (SNP), GCC > GCA (A6A) in SDHB was identified in all patients. This SNP in SDHB is found in nearly all Japanese people [13]. The patient with the novel heterozygous nonsense mutation was a 36year-old man who had been referred to Hokkaido University Hospital for further examination of a left peri-adrenal lesion. His height was $176 \mathrm{~cm}$, weight was $80 \mathrm{~kg}$, blood pressure was $117 / 84 \mathrm{mmHg}$ without medication, and pulse rate was $62 / \mathrm{min}$ with regular sinus rhythm. Hematological and biochemical tests showed no abnormalities. Serum and urine catecholamines and their metabolite levels are shown in Table 3. Abdominal computed tomography (CT) scan revealed a left peri-adrenal mass of $6.5 \mathrm{~cm}$ in diameter (Fig. 2) and ${ }^{131}$ I-metaiodobenzylguanidine $\left({ }^{131} \mathrm{I}-\mathrm{MIBG}\right)$ scintigraphy revealed radioactive iodide uptake only in this lesion. The tumor was laparoscopically resected and pathologically diagnosed as solitary sporadic PGL. He had no family history of PGL. He did not have hypertension, diabetes nor other endocrinological abnormalities.

Patients with a mutation in $S D H B$ are known to have the following features. First, they have a high prevalence of abdominal PGL with malignant potential as the initial tumor. Second, patients typically show hypersecretion of noradrenaline and/or dopamine with lower secretion of adrenaline. This probably reflects reduced expression of phenylethanolamine - $\mathrm{N}$ - methyl - transferase, an enzyme that exists almost only in medullary chromaffin cells and converts noradrenaline to adrenaline. However, $10 \%$ of those tumors are biochemically silent so that diagnosis tends to be delayed by lack of symptoms until the tumor grows. Third, many patients with PGL clinically have no family history of PGL. A study in a Western country revealed that $90 \%$ (26 of 29) of patients with SDHB-mutated abdominal and thoracic PGL lacked a family history of PGL and all primary tumors but one originated from extra-adrenal locations [8]. As described above, PGL with SDHB mutations have been suggested to be primarily identified as an abdominal tumor with high malignant potential. Further, SDHB mutations are predictive of rapid metastatic spread and are associated with poor prognosis [14]. Therefore, long-term in- 
a

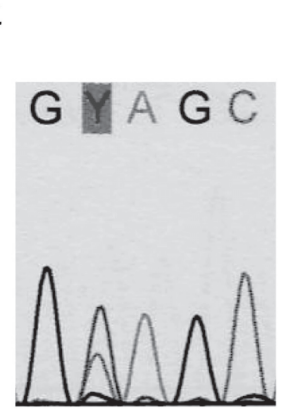

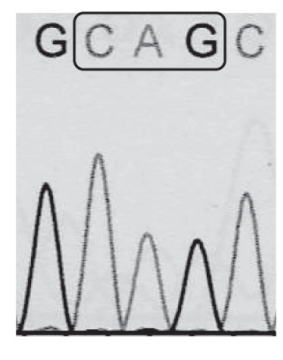

CAG

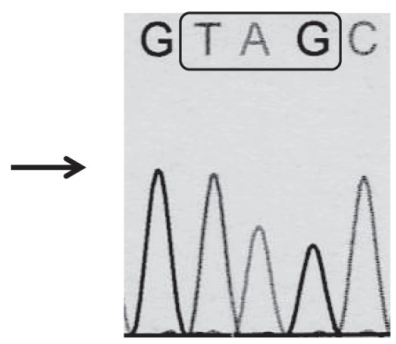

TAG

Glutamine

Stop

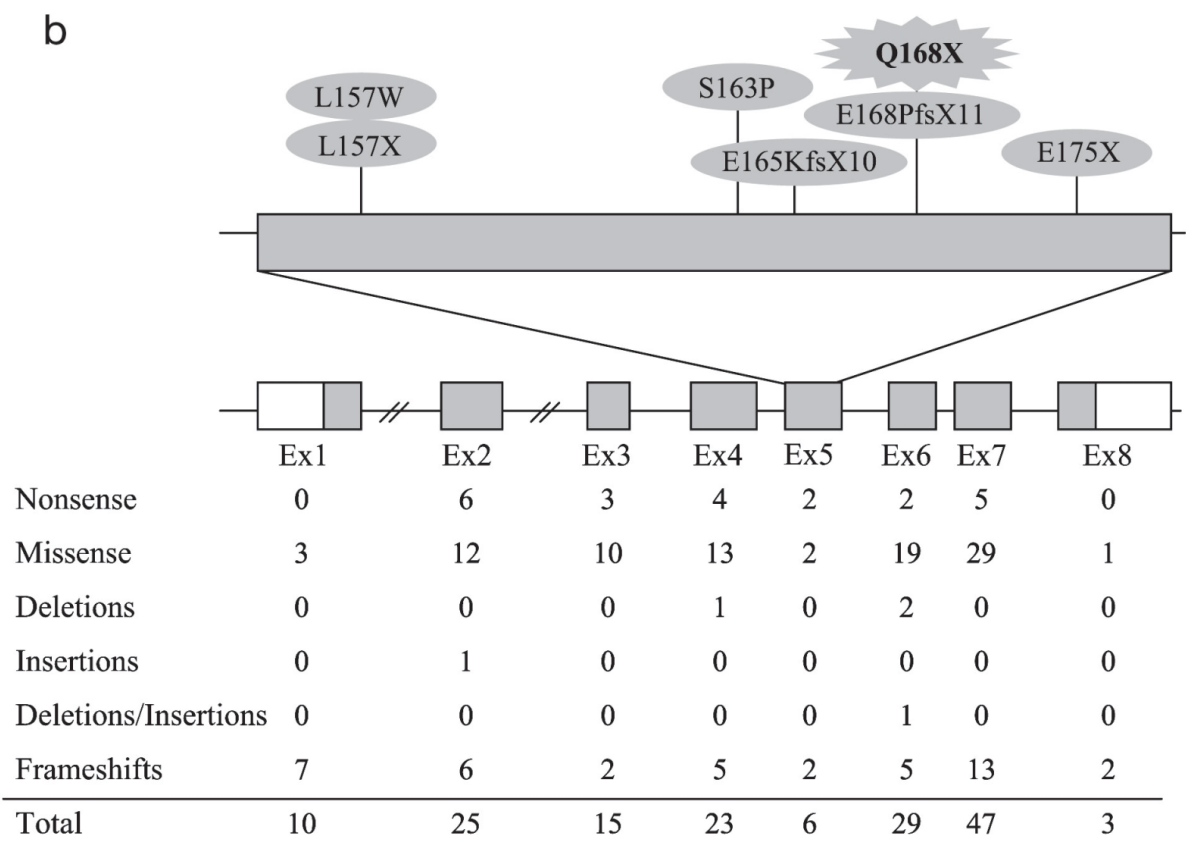

Fig. 1 a) Genetic analysis of the SDHB gene in Patient 8.

Nucleotide sequence around codon 168 in exon 5 of SDHB. Left, direct sequencing; Right, sequencing of PCR product subcloned into pGEM $\mathbb{R}-\mathrm{T}$ Easy Vector.

b) A summary of germline mutations of the SDHB gene.

The notation of mutations is based on the TCA Cycle Gene Mutation Database (http://chromium.liacs.nl/lovd_sdh/home. php?select_db=SDHB). A novel mutation (Q168X), which is identified in the present study, is described in bold. Abbreviations: fs, frameshift; Ex, exon

tensive follow-up is needed for patients who are positive for SDHB mutation.

According to Knudson's two-hit theory, patients with a germline mutation should have a somatic mutation or loss of the other allele. In general, somatic point mutations of the SDH gene seem to be very rare. To date, no somatic point mutations have been reported as part of a possible two-hit theory. In contrast, a number of studies reported a somatic deletion mutation at a site proximal to the SDH gene on the wildtype $S D H$ allele in both familial and sporadic tumors $[9,15-17]$. These findings raise the possibility that unknown tumor suppressor genes may be involved in tumorigenesis. In the present case, loss of heterozygosity $(\mathrm{LOH})$ was not examined. A more precise characterization of the somatic alterations associated 
Table 3 Results of endocrinological tests in the patient with solitary sporadic PGL with a novel heterozygous mutation in $S D H B$.

\begin{tabular}{lcc}
\hline Endocrinological tests & Result & Normal range \\
\hline Serum catecholamines & & \\
Adrenaline $(\mathrm{pg} / \mathrm{mL})$ & 19 & $<100$ \\
Noradrenaline $(\mathrm{pg} / \mathrm{mL})$ & 531 & $100-450$ \\
Dopamine $(\mathrm{pg} / \mathrm{mL})$ & 19 & $<20$ \\
Urine catecholamines & & \\
Adrenaline $(\mu \mathrm{g} / \mathrm{day})$ & 13.2 & $<28$ \\
Noradrenaline $(\mu \mathrm{g} / \mathrm{day})$ & 208 & $19-151$ \\
Dopamine $(\mu \mathrm{g} / \mathrm{day})$ & 987 & $130-1200$ \\
Metanephrine $(\mathrm{mg} /$ day) & 0.17 & $0.04-0.19$ \\
Normetanephrine $(\mathrm{mg} /$ day $)$ & 0.41 & $0.09-0.33$ \\
\hline
\end{tabular}

with $S D H$ mutation will increase our knowledge of the mechanisms underlining tumorigenesis.

Although seven patients including five PCC and two abdominal PGL in the present study were strongly suspected of being mutation carriers based on their malignant signs, only one patient with no malignant sign had genetic mutation of $S D H B$. This result was fewer than expected. A number of studies have reported that patients with abdominal PGL have a higher incidence of mutation of $S D H B$ than those with PCC. For example, an American study [5] reported that 16 of $44(36.4 \%)$ patients with abdominal PGL had SDHB mutation compared to 9 of 313 (2.9\%) patients with PCC, and similarly, another French study [6] reported that 17 of $58(29.3 \%)$ patients with thoracoabdominal PGL had SDHB mutation compared to 7 of $314(2.7 \%)$ patients with PCC. Furthermore, an American study [14] which analyzed SDHB mutation in a series of patients with malignant PCC and PGL reported that 12 of 29 (41.4\%) patients with abdominal PGL had SDHB mutation compared to 1 of 15 (6.7\%) patients with PCC. In the present study, 5 of 7 patients with malignancy had PCC and the other only 2 patients had abdominal PGL, lower rate of $S D H B$ mutation might be due to the difference of tumor origin. Another reason for the lower rate of SDHB mutation may be due to racial differences. As a result, it would be difficult to indicate an association between SDHB mutation and malignancy from this study. On the other hand, a lack of SDHD mutation in the pres-

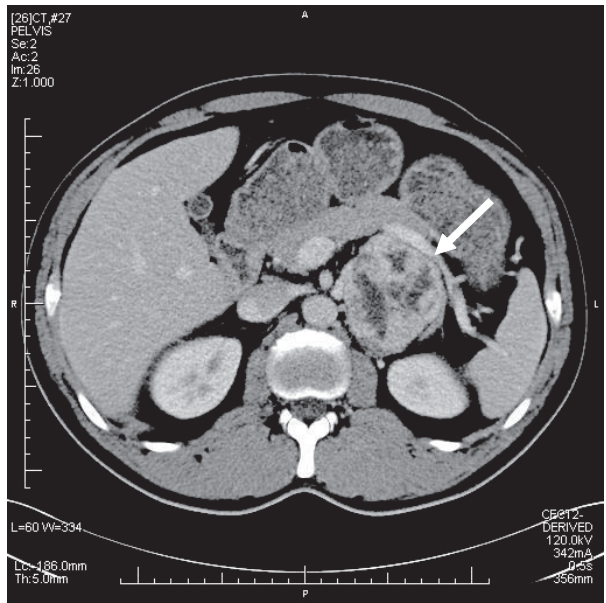

Fig. 2 Abdominal CT-scan in Patient 8. The arrow indicates the tumoral lesion in the left periadrenal gland.

ent study may have been caused by the source of tumor specimens. Because the prevalence of SDHD mutation is known to be higher at head and neck PGL than PCC or abdominal PGL $[5,7,9]$.

We did not examine other susceptibility genes, RET, $V H L$ and $N F-1$, for mutations. Indeed, a VHL-mutated parent and child were included in the present study. However, testing of all susceptibility genes in patients is not recommended from a cost-effectiveness perspective [4]. It is desirable to test for mutations after estimating the pathogenic gene from the patient's clinical characteristics. Several studies in Western countries have revealed associations between genotype and phenotype among patients and indicated the strategy as to which genes should be screened first [4]. However, there is no evidence to support that such correlations are suitable for patients in Asian countries including Japan. We analyzed $S D H$ mutations in 18 patients of which number was too small to conclude the association. Finally, we hope that genotype-phenotype analysis of $S D H$ mutations will lead to the development of an appropriate genetic screening test that would be performed on all patients with PCC and PGL.

\section{Acknowledgement}

This work was supported in part by a Grant-in-Aid for Research on Specific Diseases "HypothalamoPituitary Dysfunction" from the Ministry of Health, Labour and Welfare, Japan (C.S.). 


\section{References}

1. Astuti D, Latif F, Dallol A, Dahia PL, Douglas F, George E, Sköldberg F, Husebye ES, Eng C, Maher ER (2001) Gene mutations in the succinate dehydrogenasesubunit SDHB cause susceptibility to familial pheochromocytoma and to familial paraganglioma. Am J Hum Genet 69: 49-54.

2. Baysal BE, Ferrell RE, Willett-Brozick JE, Lawrence EC, Myssiorek D, Bosch A, van der Mey A, Taschner PE, Rubinstein WS, Myers EN, Richard CW 3rd, Cornelisse CJ, Devilee P, Devlin B (2000) Mutations in SDHD, a mitochondrial complex II gene, in hereditary paraganglioma. Science 287: 848-851.

3. Niemann S, Müller U (2000) Mutations in SDHC cause autosomal dominant paraganglioma, type 3. Nat Genet 26: 268-270.

4. Mannelli M, Castellano M, Schiavi F, Filetti S, Giacché M, Mori L, Pignataro V, Bernini G, Giachè V, Bacca A, Biondi B, Corona G, Trapani GD, Grossrubatscher E, Reimond G, Arnaldi G, Giacchetti G, Veglio F, Loli P, Colao A, Ambrosio MR, Terzolo M, Letizia C, Ercolino T, Opocher G (2009) Clinically guided screening in a large cohort of Italian patients with pheochromocytomas and/or functional or non-functional paragangliomas. J Clin Endocrinol Metab 10: 1541-1547.

5. Neumann HP, Pawlu C, Pęczkowska M, Bausch B, McWhinney SR, Muresan M, Buchta M, Franke G, Klisch J, Bley TA, Hoegerle S, Boedeker CC, Opocher G, Schipper J, Januszewicz A, Eng C (2004) Distinct Clinical Features of Paraganglioma Syndromes Associated with SDHB and SDHD Gene Mutations. JAMA 292: 943-951.

6. Amar L, Bertherat J, Baudin E, Ajzenberg C, Bressac-de B, Paillerets BB, Chabre O, Chamontin B, Delemer B, Giraud S, Murat A, Niccoli-Sire P, Richard S, Rohmer V, Sadoul J, Strompf L, Schlumberger M, Bertagna X, Plouin P, Jeunemaitre X, Gimenez-Roqueplo A (2005) Genetic Testing in Pheochromocytoma or Functional Paraganglioma. $J$ Clin Oncol 23: 8812-8818.

7. Benn DE, Gimenez-Riqueplo A, Reilly JR, Bertherat J, Burgess J, Byth K, Croxson M, Dahia PL, Elston M, Gimm O, Henley D, Herman P, Murday V, NiccoliSire P, Pasieka JL, Rohmer V, Tucker K, Jeunemaitre X, Marsh DJ, Plouin P, Robinson BG (2006) Clinical Presentation and Penetrance of Pheochromocytoma/ Paraganglioma Syndromes. J Clin Endocrinol Metab 91: 827-836.

8. Timmers HJLM, Kozupa A, Eisenhofer G, Raygada M, Adams KT, Solis D, Lenders JW, Pacak K (2007)
Clinical Presentations, Biochemical Phenotypes, and Genotype-Phenotype Correlations in Patients with Succinate Dehydrogenase Subunit B-associated Pheochromocytomas and Paragangliomas. J Clin Endocrinol Metab 92: 779-786.

9. Pasini B, Stratakis CA (2009) SDH mutation in tumorigenesis and inherited endocrine tumours: lesson from the phaeochromocytoma-paraganglioma syndromes. $J$ Intern Med 266: 19-42.

10. Lee SC, Chionh SB, Chong SM, Taschner PE (2003) Hereditary Paraganglioma Due to the SDHD M1I Mutation in a Second Chinese Family: A Founder Effect? Laryngoscope 113: 1055-1058.

11. Isobe K, Minowada S, Tatsuno I, Suzukawa K, Nissato S, Nanmoku T, Hara H, Yashiro T, Kawakami Y, Takekoshi $\mathrm{K}$ (2007) Novel Germline Mutations in the SDHB and SDHD Genes in Japanese Pheochromocytomas. Horm Res 68: 68-71.

12. Aguiar RC, Cox G, Pomeroy SL, Dahia PL (2001) Analysis of the SDHD Gene, the Susceptibility Gene for Familial Paraganglioma Syndrome (PGL1), in Pheochromocytomas. J Clin Endocrinol Metab 86: 2890-2894.

13. http://www.ncbi.nlm.nih.gov/SNP/snp ref.cgi?rs=2746462

14. Amer L, Baudin E, Burnichon N, Peyrard S, Silvera S, Bertherat J, Bertagna X, Schlumberger M, Jeunemaitre X, Gimenez-Roqueplo A, Plouin P (2007) Succinate Dehydrogenase B Gene Mutations Predict Survival in Patients with Malignant Pheochromocytomas or Paragangliomas. J Clin Endocrinol Metab 92: 3822-3828.

15. Gimm O, Armanios M, Dziema H, Neumann HP, Eng C (2000) Somatic and Occult Germ-line Mutation in SDHD, a Mitochondrial Complex II Gene, in Nonfamilial Pheochromocytoma. Cancer Res 60: 6822-6825.

16. Astuti D, Hart-Holden N, Latif F, Lalloo F, Black GC, Lim C, Moran A, Grossman AB, Hodgson SV, Freemont A, Ramsden R, Eng C, Evans DG, Maher ER (2003) Genetic analysis of mitochondrial complex II subunits SDHD, SDHB and SDHC in paraganglioma and pheochromocytoma susceptibility. Clin Endocrinol 59: 728-733.

17. Hensen EF, Jordanova ES, Minderhout I, Hogendoorn P, Taschner P, Mey A, Dwvilee P, Cornelisse CJ (2004) Somatic loss of maternal chromosome 11 causes parent-of-origin-dependent inheritance in SDHD-linked paraganglioma and pheochromocytoma families. Oncogene 23: 4076-4083. 